\title{
Cultivation Technique of Seedling Used for Raw Material of Fetal Tea
}

\author{
Ren Cui-juan $^{1,2}$, Zhou Jia-shuang ${ }^{1,2}$, Pan Jie ${ }^{1,2}$, Ye Qun ${ }^{1,2}$, Jiang Jin-zhong ${ }^{1,2, *}$ \\ ${ }^{1}$ Guizhou Bioresource Development and Utilization Key Laboratory, Guizhou Normal College, Guiyang, China \\ ${ }^{2}$ Guizhou Yuanheng Mountain Tea Seed Biological Technology Ltd Co., LTD., Guiyang, China
}

\section{Email address:}

jjz9911@163.com (Ren Cui-juan),jjz9911@163.com (Jiang Jin-zhong)

${ }^{*}$ Corresponding author

\section{To cite this article:}

Ren Cui-juan, Zhou Jia-shuang, Pan Jie, Ye Qun, Jiang Jin-zhong. Cultivation Technique of Seedling Used for Raw Material of Fetal Tea. American Journal of Agriculture and Forestry. Vol. 4, No. 2, 2016, pp. 30-34. doi: 10.11648/j.ajaf.20160402.14

Received: March 11, 2016; Accepted: April 18, 2016; Published: May 4, 2016

\begin{abstract}
Fetal tea is a new type of tea made from seedling before its big euphylla come into leaf. So the yield and quality of seedling used for raw material of fetal tea directly affect the fetal tea yield and quality; the main purpose of this paper is to explore the effect of full light, half light and dark conditions on the growth of seedling used for raw material of fetal tea, and to provide a reference basis for the production of seedling with high quality. The tea tree seeds were cultivated with water under full light, half light and dark conditions, respectively; Then quadrats were set to observed regularly germination state of seed, growth of baconic and germ, meanwhile growth of root, stem, leaf, euphylla of "germ seedling"; By comparing the difference between different illumination conditions, the appropriate light conditions were selected as follows. The number and speed of seed crack were $27.0 \%$ and $63.4 \%$ higher under full light than under dark conditions and half light, respectively; Meanwhile the number of seed crack was $28.6 \%$ higher under dark conditions than under half light. As a result, the full light was the best for cultivating seedling used for fetal tea, dark condition was middle, and half light was worst. The baconic elongation of seed were $87.7 \%$ and $93.7 \%$ higher under full light than half light and dark condition, respectively, while $3.1 \%$ higher under half light than dark condition; therefore, full light was the best condition to promote baconic growth, half light was second, dark condition was the worst. The growth length of germ were $76.0 \%$ and $92.0 \%$ lower under half light and under dark condition than under full light, respectively, while $66.6 \%$ lower under dark condition than under half light, hence, full light was the best condition to promote germ growth, half light was second, and dark condition is the worst. Based on above results, it was concluded that cultivating tea seed with water under full light can obtain higher output of seedling used for raw material of fetal tea.
\end{abstract}

Keywords: Fetal Tea, Tea Tree Seed, Germ, Germ Seedling

\section{胎茶原料苗培育技术初探}

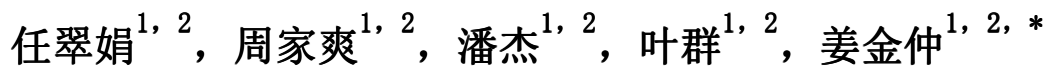 \\ ${ }^{1}$ 贵州省生物资源开发利用特色重点实验室, 贵州师范学院, 贵阳, 中国 \\ ${ }^{2}$ 贵州元亨山茶叶籽生物科技有限公司, 贵阳, 中国
}

\section{邮箱}

jjz9911@163. com（任翠娟), jjz9911@163. com（姜金仲）

摘要：胎茶是以大真叶前的实生苗为原料制成的新型茶叶，因此，胎茶原料苗的产量及质量直接影响胎茶的产量及质 量; 本文的主要目的是探索全光照、半光照及全暗条件对胎茶原料苗生长的影响, 为生产优质胎茶原料提供参考依据。 通过将茶树种子在全光照、半光照及全暗条件下进行水培; 设置样方定期观察种子萌发情况, 胚根、肧芽生长情况及 “胚 
芽幼苗” 根、茎、叶和子叶的生长情况, 比较了不同光照条件下的差异, 结果如下。从种子裂口的数量及速度看, 全 光照裂口总数高于全暗条件和半光照条件, 分别高出 $27.0 \%$ 及 $63.4 \%$, 而全暗条件比半光照的裂口总数多出 $28.6 \%$, 因此, 全光照条件是培育胎茶种子萌发的较佳条件, 全暗条件次之, 半光照条件最差; 从种子胚根伸长生长的情况看, 全光 照条件下胚根生长量大于半光照条件和全暗条件, 分别大出 $87.7 \%$ 及 $93.7 \%$, 而半光照条件胚根生长量大全暗条件 $3.1 \%$, 因此, 全光照条件是促进种子胚根生长的最佳条件, 半光照条件次之, 全暗条件最差; 从胚芽生长长度看, 半光照条 件和全暗条件种子胚芽整体生长低于全光照条件, 分别低 $76.0 \% 、 92.0 \%$, 而全暗条件比半光照条件低 $66.6 \%$, 因此, 全 光照条件是促进种子胚芽生长的最佳条件, 半光照条件次之, 全暗条件最差。综合分析结果可以结论：全光照条件下 水培茶树种子，可以获得较高的胎茶原料苗产量。

关键词: 胎茶, 茶树种子, 胚芽, 肧芽幼苗

\section{1. 引言}

胎茶是以茶树 (Camellia sinensis) 种子的幼苗为原 料生产而成的一种新型茶叶。目前, 中国有19个省生产茶 叶, 拥有茶园 160 万ha, 每年产茶籽约 84 万t, 由于目前尚 无有效的茶树种子开发利用方法, 这些茶树种子仅有小部 分加工成茶叶籽仁销往日本、韩国及台湾地区, 其余大部 分被自然烂掉, 造成茶叶籽资源的严重浪费。胎茶是指用 大真叶前的茶树实生苗为原料制作而成的茶叶; 胎茶具有 较高的茶氨酸含量及较低的茶多酚含量, 因此, 是一种具 有开发为 “少儿功能茶” 的巨大潜力; 同时，也可使被浪 费的茶叶籽资源得到充分利用。姜金仲等开展了胎茶生产 方案篮选研究，在 “胎冠”、“胎珠”、“胎尖”、“胎 蝶”及 “白化苗栽培”五种胎茶生产方案中优选出 “胎尖” 方案为最佳胎茶生产方案 [1]; 生产的“胎尖” 茶的茶氨 酸含量比普通茶叶高 $75 \%$, 咖啡因及茶多酚含量比普通茶 叶分别低 $4 \%$ 和 $30 \%$; 茶氨酸特别有利于少儿的智力发展, 较低的咖啡因及茶多酚含量能有效减少饮茶对少儿的兴 奋作用，所以，“胎尖” 茶可以开发为少儿专用饮品。关 于胎茶原料苗生产研究实际上是如何让茶叶籽在特定条 件下萌发, 并朝着有利于胎茶生产方向生长发育的研究。 关于种子萌发前人做过大量研究, 张敏等研究了影响种子 萌发的光照属性、光与水/热耦合作用和种子的光属性 (光 敏色素) 与种子萌发的关系, 并明确了光调控种子萌发的 生态意义 [2]。徐恒恒等介绍了近年来种子萌发及其调控 的研究进展, 主要包括了种子萌发过程中的重要生理事 件，其中提到了种子的成功萌发和正常成苗决定植物物 种的繁衍与生存 [3]。杨广容等介绍了不同茶树品种茶籽 发芽特性, 并强调指出有效促进茶树种籽萌发是茶树种子 实生苗培育和促进茶树种质资源利用的重要条件 [4]。郭 春芳等研究了不同土壤水分条件下茶树 (铁观音和福鼎大 白茶) 光合作用及其水分利用效率 (WUE) 的变化, 指出不同 土壤水分处理对茶树净光合速率 $(\mathrm{Pn})$ 、蒸腾速率 $(\mathrm{Tr})$ 、气 孔导度 (Gs)、WUE等生理指标及其日变化均产生明显影响; 水分胁迫下茶树的Pn、Tr、Gs都下降，WUE日平均值的降 幅比Pn的小 [5]。目前虽然已优选出生产 “胎尖” 茶为胎 茶生产方案, 并指出 “胎尖” 方案的生产原料是未出土的 茶树种子嫩苗, 但对未出土茶树种子嫩苗的培育方法未见 研究报道。本文试图以 3 种不同光照条件的无土栽培方式
培育茶树种子幼苗, 观察分析其培育效果, 以为制定较好 的胎茶原料苗生产方案提供参考依据。

\section{2. 材料与方法}

\section{1. 试验材料}

试验用茶树种子于 2014 年2月购自中国河南省信阳市 董寨国家自然保护区种子公司, 以每麻袋 $50 \mathrm{~kg}$ 放入室内 自然保存, 2015年5月进行育苗试验。种子为小叶茶系, 千粒重 $495.3 \mathrm{~g}$, 萌发率 $93.5 \%$, 种子含水量 $14.5 \%$ 。

\section{2. 试验方法}

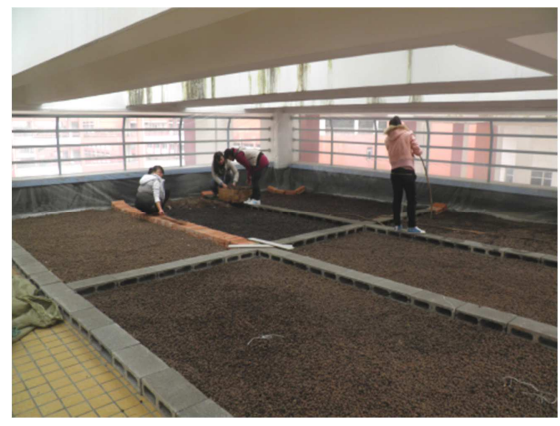

图1 茶树种子播种。

\subsection{1. 试验设置}

试验在贵州师范学院进行, 按培育点采光强度设 3 个 处理: 全光照阳台上培育; 半光照阳台上培育; 全暗条件 下室内培育。在全光照阳台上设 4 个试验小区 $(1.2 \mathrm{~m} \times 3.0$ $\mathrm{m})$, 每小区中央位置设 1 个观察方框 $(10.0 \mathrm{~cm} \times 10.0 \mathrm{~cm})$, 分别标记为 1 号、 2 号、 3 号和 4 号; 半光照阳台上设 1 个试 验小区 $(1.2 \mathrm{~m} \times 9.0 \mathrm{~m})$ ，小区中设 3 个观察方框 $(10.0$ $\mathrm{cm} \times 10.0 \mathrm{~cm}$ ），其中 1 个得到了有效数据, 记为 5 号; 全 暗栽培条件下设 1 个试验小区 $(2.0 \mathrm{~m} \times 5.0 \mathrm{~m})$ ，小区中 设 3 个观察方框 $(10.0 \mathrm{~cm} \times 10.0 \mathrm{~cm})$, 分别记为 6 号、7 号和 8 号。

\subsection{2. 种子播种方法}

在每个试验小区底部铺上塑料膜, 塑料膜上平铺 $5 \mathrm{~cm}$ 厚的松针土, 浇透水, 按照上述设置, 在每个小区的观察 
方框内撒播约 $4 \mathrm{~cm}$ 厚的茶树种子（100粒种子），然后在 种子上方盖上 $5 \mathrm{~cm}$ 厚的松针, 浇透水(图1)。

\section{2. 3. 种子生长情况观察及指标测定}

播种后每天掀开观察框上方的松针, 观察其中种子 的生长情况, 然后再将松针原样盖好, 每周测定种子萌发 情况。具体测定内容为: 茶树种子开始裂口阶段, 统计裂 口种子数量; 幼苗长出胚根阶段, 从每个观察框萌发种子 中挑选 10 株胚根最长的幼苗, 用游标卡尺测量胚根长度; 幼苗嫩茎明显伸长阶段, 从每个观察框中挑选 10 株嫩茎最 长的植株, 用游标卡尺测量嫩茎长度。

\subsection{4. 幼苗形态界定}

由于胎茶的生产原料是尚未出土或尚被松针所覆盖 的茶树种子幼苗, 对这个时期的幼苗开展研究必须首先给 出我们界定的幼苗形态（图2）。茶叶籽从萌发到大真叶 出现之前这段时间称为胚芽期, 胚芽分化出大真叶时区分 为幼叶及幼茎, 幼叶即刚分化出的大真叶, 幼茎即胚芽的 嫩茎（从种子表皮到第一片大真叶之间嫩茎，包括3片小 真叶）。分化出大真叶、但尚未长出种子上面覆盖物（松 针) 的胚芽 (或大真叶尚未展开前的胚芽) 后文称之为 “胚 芽幼苗” , 是胎茶的生产原料。茶叶籽萌发过程中先后长 出三片形似真叶的小叶, 但未来却不能真正发育为真叶, 直到第四片小叶出现时, 才能真正在未来发育为真叶。

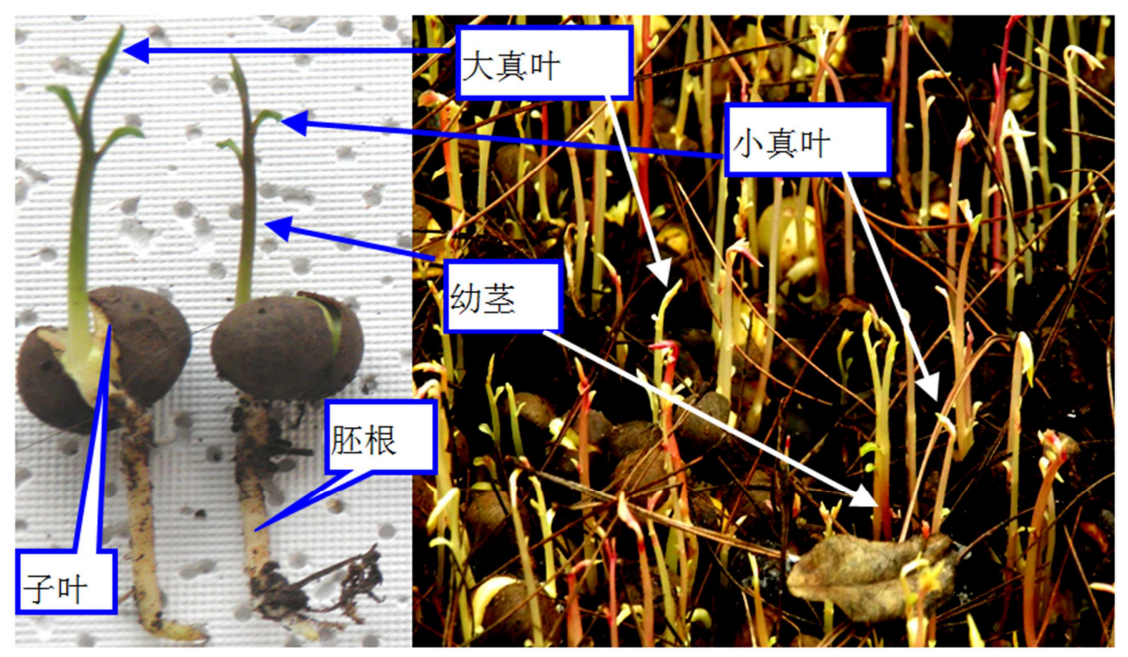

\section{3. 统计分析}

试验数据用 Excel 2012 版本软件进行统计（整理）, 用 SPSS19.0 版本软件进行数据分析。

\section{3. 结果与分析}

\section{1. 不同光照条件下茶树种子的萌发情况}

茶树种子萌发情况用在同一时间点上观察框中 100 粒 种子裂口的个数表示。由表 1 可以看出, 全光照及全暗条 件下种子裂口数增加速度基本同步, 在播种后的第 5 周和
图2 茶树幼苗形态。

第7周分别达到最高点, 半光照条件下的种子裂口数达到 最高点明显较晚, 播种后第 8 周时才出现。由表 1 可知, 全 光照条件下种子裂口总数高于全暗条件和半光照条件, 分 别高出 $27.0 \% 、 63.4 \%$, 且差异显著 $(P<0.05)$, 说明全 光照栽培环境能为种子裂口提供比较适宜的温度, 使种子 裂口数增加; 而全暗条件比半光照的裂口总数多出 $28.6 \%$, 说明半光照条件下种子裂口总数最少, 但与全暗条件下的 种子裂口总数之间差异不显著（P>0.05）。由此可见， 不同光照条件对茶树种子萌发效果不同, 以全光照条件最 佳, 全暗条件次之, 半光照最差。

表1 茶树种子裂口数及方差分析。

\begin{tabular}{llllllllllllll}
\hline 观察时间 & 1 & 2 & $\mathbf{3}$ & $\mathbf{4}$ & $\mathbf{5}$ & $\mathbf{6}$ & $\mathbf{7}$ & $\mathbf{8}$ & $\mathbf{9}$ & $\mathbf{1 0}$ & $\mathbf{1 1}$ & $\mathbf{1 2}$ & 平均 \\
\hline 全光 & 11 & 33 & 45 & 45 & 58 & 58 & 56 & 51 & 47 & 44 & 46 & 42 & $45 \mathrm{~b}$ \\
半光 & 1 & 22 & 24 & 28 & 33 & 39 & 44 & 57 & 24 & 26 & 22 & 8 & $27 \mathrm{a}$ \\
全暗 & 5 & 29 & 41 & 44 & 49 & 49 & 50 & 41 & 43 & 40 & 18 & 13 & $35 \mathrm{a}$ \\
\hline
\end{tabular}

注: 显著水平为 $\mathrm{a}=0.05, \mathrm{~b}$ 表示差异显著, 以下方差分析相同。

\section{2. 不同光照条件下茶树种子胚根的生长情况}

茶树种子萌发首先长出胚根, 胚根生长情况直接影响 胚芽的生长状况, 胚芽的生长状况又会影响胚芽幼苗的生 长状况, 而胚芽幼苗正是胎茶的生产原料。从表 2 可以看 出, 全光照和全暗栽培条件下, 茶树种子播种后第1周开 始长出胚根, 半光照条件下, 播种后第 2 周才长出胚根,
说明全光照和全暗栽培条件有利于种子胚根提前生长, 半 光照条件延迟种子胚根生长; 全光照条件下种子胚根生长 长度长于另外两种光照条件, 半光照条件下胚根生长长度 整体上长于全暗栽培条件; 播种后第 5 周以前, 全光照和 全暗条件下胚根生长速度最快, 第 5 10 周整体趋于稳定, 而半光照条件下, 胚根从种子中伸出的一周内, 生长速度 
最快, 第 $3 \sim 10$ 周生长长度总体趋于稳定; 从第 9 周开始全 光照条件下胚根长度生长开始减缓, 另外两种光照条件下 从第 10 周开始胚根长度生长也开始减缓, 胚根开始发育成 主根。由表 2 可知, 全光照条件下胚根生长量大于半光照 条件和全暗条件, 分别大出 $87.7 \% 、 93.7 \%$, 且差异显著 $（ p<0.05 ）$ ，说明全光照条件更有利于茶树种子胚根的生
长; 而半光照条件胚根生长量大全暗条件 $3.1 \%$, 说明全暗 条件下种子胚根生长整体最慢, 但与半光照条件下的种子 胚根生长长度间差异不显著（ $p>0.05 ） 。 由$ 此可见, 不同 光照条件对茶树种子胚根生长影响不同, 以全光照条件最 佳, 半光照次之, 全暗条件最差。

表2 种子胚根生长长度及方差分析。

\begin{tabular}{llllllllllllll}
\hline 观察时间 & $\mathbf{1}$ & $\mathbf{2}$ & $\mathbf{3}$ & $\mathbf{4}$ & $\mathbf{5}$ & $\mathbf{6}$ & $\mathbf{7}$ & $\mathbf{8}$ & $\mathbf{9}$ & $\mathbf{1 0}$ & $\mathbf{1 1}$ & $\mathbf{1 2}$ & 平均 \\
\hline 全光 & 0 & 2 & 3 & 5 & 6 & 6 & 7 & 7 & 7 & 6 & 7 & 6 & $5 \mathrm{~b}$ \\
半光 & 0 & 0 & 3 & 3 & 3 & 3 & 3 & 5 & 3 & 4 & 4 & 2 & $3 \mathrm{a}$ \\
全暗 & 0 & 1 & 2 & 3 & 3 & 4 & 4 & 4 & 4 & 3 & 2 & 2 & $3 \mathrm{a}$ \\
\hline
\end{tabular}

\section{3. 不同光照条件下茶树种子胚芽的伸长情况}

胚芽是胚芽幼苗未分化出大真叶前的生长阶段, 其生 长情况直接影响到胚芽幼苗的生长情况, 进而影响到胎茶 原料的产量。从表 3 可以看出, 全光照栽培条件下, 茶树 种子播种后第 5 周开始长出胚芽, 半光照和全暗栽培条件 下，播种后第6周才长出胚芽。说明全光照栽培条件有利 于种子胚芽提前长出, 半光照和全暗栽培条件延迟种子胚 芽长出; 全光照条件下种子胚芽生长长度长于另外两种栽 培条件, 半光照条件下胚芽生长长度整体虽然长于全暗栽
培条件, 但两种栽培条件下的胚芽生长速度都较小。由表 3 可知, 半光照条件和全暗条件种子胚芽整体生长少于全 光照条件, 分别少出 $76.0 \% 、 92.0 \%$, 且差异显著 $(p<0.05)$, 说明全光照栽培条件最有利于种子胚芽的伸长生长; 而全 暗条件比半光照条件少出 $66.6 \%$, 说明全暗条件下种子胚 芽生长整体最慢, 但与半光照条件下的种子胚芽生长长度 间差异不显著（p>0.05）。由此可见，不同光照条件对茶 树种子胚芽生长影响不同, 以全光照条件最佳, 半光照次 之, 全暗条件最差。

表3 种子肧芽生长长度及方差分析。

\begin{tabular}{llllllllllllll}
\hline 观察时间 & $\mathbf{1}$ & $\mathbf{2}$ & $\mathbf{3}$ & $\mathbf{4}$ & $\mathbf{5}$ & $\mathbf{6}$ & $\mathbf{7}$ & $\mathbf{8}$ & $\mathbf{9}$ & $\mathbf{1 0}$ & $\mathbf{1 1}$ & $\mathbf{1 2}$ & 平均 \\
\hline 全光 & 0 & 0 & 0 & 0 & 0 & 1 & 2 & 3 & 3 & 4 & 5 & 7 & $2 \mathrm{~b}$ \\
半光 & 0 & 0 & 0 & 0 & 0 & 0 & 0 & 2 & 1 & 1 & 1 & 1 & $1 \mathrm{a}$ \\
全暗 & 0 & 0 & 0 & 0 & 0 & 0 & 0 & 0 & 0 & 1 & 1 & 0 & $0 \mathrm{a}$ \\
\hline
\end{tabular}

\section{4. 不同光照条件下茶树种子 “肧芽幼苗” 根、茎、叶和 子叶的生长量}

肧芽分化出大真叶后, 就进入了胚芽幼苗期, 胚芽幼 苗的产量直接影响胎茶的原料的产量, 肧芽幼苗根、茎、 叶之间的比例又会影响到胎茶的风味及质量; 由表4可以 看出, 半光照条件下胚芽幼苗根、茎、叶及子叶鲜重高于 全暗和全光照栽培条件, 其原因可能是半光照条件下胚芽 幼苗既能进行光合作用产生光合产物, 为胚芽幼苗生长提 供能量; 同时进行呼吸作用, 又能为胚芽幼苗进行光合作 用提供原材料。这样同时进行双向的循环运动, 使胚芽幼 苗加快新陈代谢、物质循环、能量流动, 在此过程中积累 大量的代谢产物, 满足肧芽幼苗根、茎、叶和子叶鲜重的 增加。由表4可知, 半光照条件下茶树种子胚芽幼苗根、 茎、叶和子叶的鲜重高于另外两种光照条件, 且差异显著 $(p<0.05)$ ，说明半光照栽培条件更有利于茶树种子肧芽 幼苗根、茎、叶和子叶鲜重的增加; 全光照栽培条件下茶 树种子胚芽幼苗茎、根、叶和子叶的鲜重整体最低, 但与 全暗条件下茶树种子胚芽幼苗根、茎、叶和子叶鲜重间差 异不显著（p>0.05）。由此可知, 不同光照条件对茶树种 子胚芽幼苗根、茎、叶和子叶鲜重的影响不同, 以半光照 条件最佳, 全暗条件次之, 全光照最差。
表4 幼苗茎、根、叶和子叶鲜重及方差分析。

\begin{tabular}{llllll}
\hline 观察时间 & 茎重 & 根重 & 叶重 & 子叶重 & 平均 \\
\hline 全光 & 0.9 & 2.7 & 0.4 & 19.6 & $5.9 \mathrm{a}$ \\
半光 & 1.4 & 4.0 & 0.6 & 28.6 & $8.6 \mathrm{~b}$ \\
全暗 & 1.2 & 2.8 & 0.6 & 23.2 & $7.2 \mathrm{a}$ \\
\hline
\end{tabular}

\section{4. 讨论}

本研究分别在全光照、半光照及全暗条件下对茶树种 子的萌发及胚芽生长情况进行了试验研究, 研究结果表 明: 从种子裂口的数量及速度看, 全光照条件是培育胎茶 原料苗的较佳条件, 全暗条件次之, 半光照条件最差; 从 胚根伸长生长的情况看, 以全光照条件最佳, 半光照次之, 全暗条件最差; 从胚芽生长情况可知, 以全光照条件最佳, 半光照次之, 全暗条件最差; 从胚芽幼苗茎、根、叶和 子叶鲜重的增加看, 以半光照条件最佳, 全暗条件次之, 全光照最差。本研究的这些结果比张敏等 [2]研究光对种 子萌发的影响更具体和深入。

目前关于胎茶原料苗培育技术的研究未见报道。关于 种子促萌措施及茶叶树种子育苗的研究倒是有一些。间兴 富等研究结果表明光照能通过加速或延迟种子萌发的进 程、或改变幼苗活力指数和萌发指数而影响种子萌发的质 量 [6]。王贵元等 $[7]$ 、间兴富等 $[8]$ 研究了温度对枇杷种 子萌发的影响, 结果表明, 不同温度下, 种子萌发数量不 同以及种子萌发速度快慢不同。 
李萌研究了不同处理对茶籽萌发和茶苗生长的影响, 其中选用低温、激素、剥皮、不剥皮4种处理进行正交组 合对茶籽进行处理, 并观察其对茶籽萌发及生长的影响。 结果表明对茶籽的萌发及生长有很好促进效果的配比是: 先用低浓度的 $(100 \mathrm{mg} / \mathrm{L})$ 的GA3、6-BA对茶籽进行前期处 理, 后播种在施用了硫磺包裹的尿素的土壤中 [9]。这种 做法会显著地提升茶籽的发芽率和茶苗的生长速度 [10]。 而本研究主要深入了解光照强度对茶树种子的生长影响。

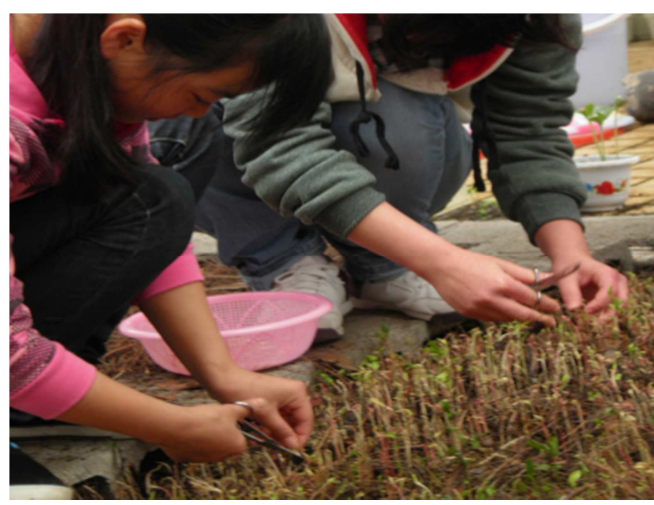

图3 胎茶原料苗采摘。

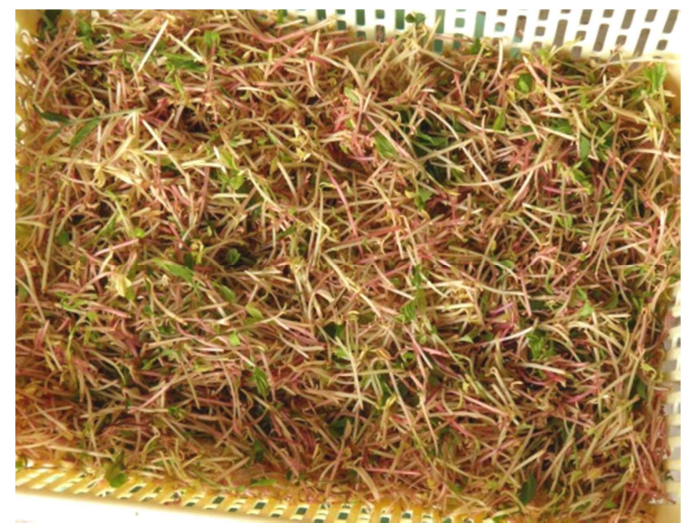

图4 采摘的胎茶原料苗。

郭春芳等研究说明不同土壤水分处理对茶树净光合 速率 $(\mathrm{Pn})$ 、蒸腾速率 $(\mathrm{Tr})$ 、气孔导度 $(\mathrm{Gs})$ 、WUE等生理指 标及其日变化均产生明显影响以及水分胁迫下茶树的Pn、 Tr、Gs都下降, WUE日平均值的降幅比Pn的小 [5]。而本次 研究中没有深入涉及这方面的内容。

茶树种子胚芽幼苗是胎茶的生产原料（图3，图4）, 其生长情况及总产量直接影响到胎茶的产量; 茶树种子胚 芽幼苗生长过程中会受到多种因素的影响, 比如, 栽培基 质、水分条件、温度、及激素处理等, 光照条件只是其中 一个; 本文只对关照条件作了研究, 因此, 以后还需要对 其他因素进行深入研究, 才能找到茶树种子胚芽幼苗的最 佳生长条件组合。

\section{5. 结论}

本研究结果表明, 不同光照条件对茶树种子的生长影 响程度不同, 其中, 全光照条件下, 茶树种子的萌发效果 最佳, 茶树种子胚根的生长状况最好, 茶树种子胚芽的伸 长速度最快, 由此可知, 利用茶树种子在全光照条件下进 行无土栽培可获得较好的胎茶原料苗。

\section{致谢}

基金项目: 贵州省国家级大学生创新创业计划项目 （201359）;国家自然科学基金项目 (31460405)

\section{参考文献}

[1] Jiang J Z, Huang Y F, Wang C Y, Ren C J, Pan C. 2014. "Fetus tea" and selection of its cultivation program[J].Applied Mechanics and Materials, Vol. 448-453pp1093-1098.

[2] 张敏, 朱教君, 间巧玲. 2012. 光对种子萌发的影响机理研究 进展 [J]. 植物生态学报, 36 (8) : 899-908.

[3] 徐恒恒, 黎妮, 刘树君, 王伟青, 王伟平, 张红, 程红炎, 宋松 泉. 2014. 种子萌发及其调控的研究进展 [J]. 作物学 报, 40(7):1141-1156.

［4］杨广容, 邵宛芳, 陶梅, 杨琴, 李家华. 2013. 不同茶树品种种 子萌发特性的研究 [J]. 云南农业大学学 报, 28(6) : 769-774.

［5］郭春芳, 孙云, 张木清. 2008. 不同土壤水分对茶树光合作用 与水分利用效率的影响 $[\mathrm{J}]$. 福建林学院学 报, 28(4):333-337.

［6］间兴富, 曹敏. 2006. 光照和温度对望天树种子萌发的影响 [J]. 植物学通报, 23 (6) :642-650.

［7］王贵元, 王琴. 2015. 不同温度、不同GA3浓度处理对枇杷种 子萌发及幼苗生长的影响 $[\mathrm{J}]$. 天津农业科 学, 21 (1) : 110-113.

[8］间兴富, 王建礼, 周立彪. 2011. 光照对辽东栋种子萌发和幼 苗生长的影响, 应用生态学报, 22(7) : 1682 -1688

[9] 李萌. 2007. 不同处理对茶籽萌发和茶苗生长的影响 [D]. 山东农业大学.

[10］韩晓阳, 张丽霞, 王日为. 2010. 茶树育苗基质的笁选及其理 化特性的研究, 山东农业科学, (1) : 36-39 